
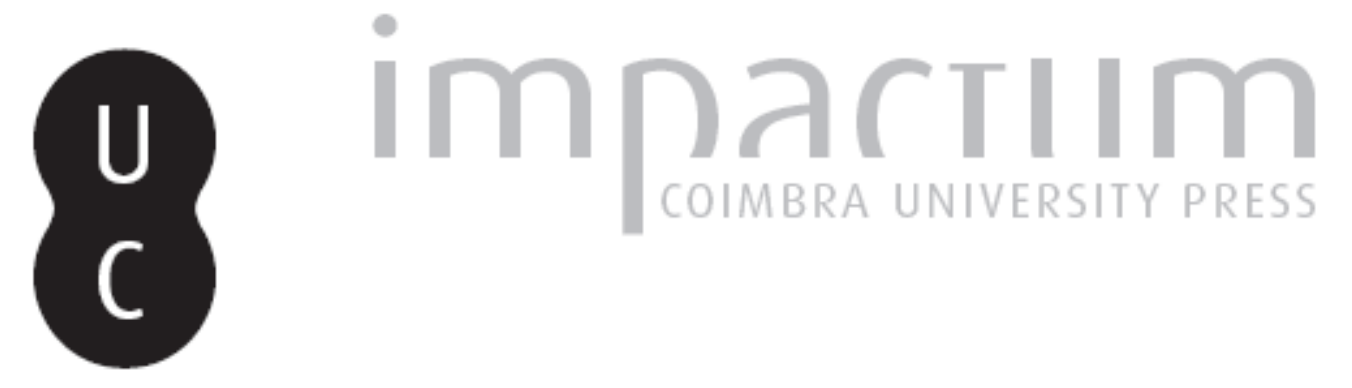

\title{
A educação de um príncipe no período pombalino
}

Autor(es): $\quad$ Silva, Maria Beatriz Nizza da

Publicado por: Imprensa da Universidade de Coimbra

URL persistente:

URI:http://hdl.handle.net/10316.2/43869

DOI:

DOI:https://doi.org/10.14195/2183-8925_4-1_13

Accessed : $\quad$ 26-Apr-2023 15:46:47

A navegação consulta e descarregamento dos títulos inseridos nas Bibliotecas Digitais UC Digitalis, UC Pombalina e UC Impactum, pressupõem a aceitação plena e sem reservas dos Termos e Condições de Uso destas Bibliotecas Digitais, disponíveis em https://digitalis.uc.pt/pt-pt/termos.

Conforme exposto nos referidos Termos e Condições de Uso, o descarregamento de títulos de acesso restrito requer uma licença válida de autorização devendo o utilizador aceder ao(s) documento(s) a partir de um endereço de IP da instituição detentora da supramencionada licença.

Ao utilizador é apenas permitido o descarregamento para uso pessoal, pelo que o emprego do(s) título(s) descarregado(s) para outro fim, designadamente comercial, carece de autorização do respetivo autor ou editor da obra.

Na medida em que todas as obras da UC Digitalis se encontram protegidas pelo Código do Direito de Autor e Direitos Conexos e demais legislação aplicável, toda a cópia, parcial ou total, deste documento, nos casos em que é legalmente admitida, deverá conter ou fazer-se acompanhar por este aviso.

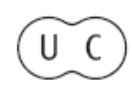




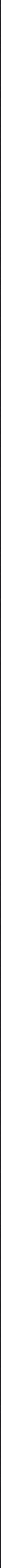


MARIA BEATRIZ NIZZA DA SILVA *

\section{A EDUCAÇÃO DE UM PRINCIPE NO PERIODO POMBALINO}

Muito se tem escrito sobre as reformas pombalinas dos Estudos Menores e da Universidade. A documentação referente ao ensino elementar foi cuidadosa e pacientemente coligida pelo saudoso A. A. Banha de Andrade ( ${ }^{1}$ ), mas talvez ain. da não tenham sido submetidas a uma análise mais atenta as instruções dadas por D. José I para a educação de seu neto, o Príncipe da Beira, D. José, datadas do Palácio de Nossa Senhora da Ajuda a 7 de Dezembro de 1768, de que existem cópias quer no Arquivo Nacional do Rio de Janeiro, quer no Instituto Histórico e Geográfico Brasileiro $\left({ }^{2}\right)$.

A historiografia portuguesa parece aceitar a versão de que Pombal procurou que fosse dada ao Príncipe da Beira a sucessão directa de seu avô, projecto que teria sido viável pela adopção da Lei Sálica, que impede às mulheres o acesso ao trono $\left({ }^{3}\right)$. Aceitando como certo este projecto pombalino de excluir D. Maria da sucessão ao trono, compreende-se a importância de que se revestem estas instruções para a educação do herdeiro, então com 7 anos.

A primeira parte deste documento ocupa-se unicamente com as normas referentes ao convívio do príncipe com aqueles que o serviam, procurando apresentar como normal no ceri-

* Faculdade de Filosofia, Letras e Ciências Humanas da Universidade de São Paulo.

(') António Alberto Banha de Andrade, A reforma pombalina dos estudos secundários (1759-1771). (Contribuição para a história da pedagogia em Portugal), 2. ${ }^{\circ}$ volume (Documentação), Coimbra, 1981.

$\left({ }^{2}\right)$ Arquivo Nacional do Rio, Cod. 1093-1; Instituto Histórico e Gcográfico Brasileiro, Lata 61, documento 4.

(') Dicionário de História de Portugal, dirigido pcr Joel Serrão, volume II. 
monial da Corte a segregação. da criança e o controlo dos seus contactos sociais: $\alpha A$ dignidade, a decência e o costume das Cortes fazem necessário que as conversações com o Príncipe sejam reduzidas somente aos Gentis-homens da Câmara, Moços da Guarda-roupa, que o servem e aos ministros do meu Conselho de Estado, sem que se possa permitir que os reposteiros, varredores, cabeleireiros, ou quaisquer outras pessoas destes semelhantes foros, tenham com o mesmo Príncipe a menor prática, antes pelo contrário deverão sair do quarto, logo que houverem feito o serviço, que necessário for" $\left.{ }^{(}\right)$.

Aos 7 anos de idade, chegara o momento de retirar o príncipe do ambiente infantil e da influência feminina, para iniciá-lo numa forma de aprendizado que exigia aposentos separados, num rito de iniciação ao mundo masculino. $O$ herdeiro do trono tinha servidores nomeados pelo rei, aos seus aposentos só podiam subir pessoas da família real, ministros com assento e voto no Conselho de Estado, o seu confessor, Frei Manuel do Cenáculo $\left({ }^{5}\right)$, o seu instrutor de ler e escrever, António Domingues do Passo.

Como vemos, nesta primeira fase da educação do Príncipe, aquele que depois seria o seu mestre, Fr. Manuel do Cenáculo, desempenhava apenas o papel de confessor e portanto não seria ele o responsável pelos conhecimentos então ministrados. Reconhecia-se neste documento que «a tenra idade, e a compleição do Príncipe não permitem que a sua atenção e a memória sejam gravadas com todos os documentos religiosos e políticos que lá em mais adiantados anos se farão oportunos" $\left(^{6}\right)$.

(') Francisco da Gama Caeiro, no seu livro Frei Manuel do Cenáculo. Aspectos da sua actuação filosófica, Lisboa, 1959, cita um manuscrito da Biblioteca Pública de tvora que parece corresponder a esta primeira parte das instruções. Trata-se da «Cópia da instruçãa e ordens que Sua Majestade foi servido dar para se observarem no quarto do Príncipe Nosso Senhor» (Cód. n. ${ }^{\circ}$ CXXXI/1-17, fls. 231-237). Pelo resumo que Gama Caeiro faz deste manuscrito de Evora, o seu conteúdo parece idêntico ao dos manuscritos conservados no Brasil, com algumas diferenças: no documento que estamos analisando não há qualquer referência ao atentado dos Távoras, nem se cogita de que ao Príncipe se ensinem leis (ob. cit., pp. 88-89).

(5) Gama Caeiro, na obra citada, analisa o papel de Fr. Manuel do Cenáculo como mestre do Príncipe da Beira desde os 9 até aos 15 anos, mas no momento em que são redigidas as instruções de 1768 Cenáculo era ainda apenas o confessor (pp. 85-89).

( $\left.{ }^{\circ}\right)$ Só mais tarde Cenáculo se encarregou de fazer e ensinar ao Príncipe, por exemplo, uma «selecção das leis, excluindo as do foro judicial e dos magistrados civis» (Caeiro, ob. cit., p. 86). 
O primeiro passo na educação desta fase consistia na organização do tempo, pois era necessário que o Príncipe se acostumasse desde logo "a repartir as horas, para viver com método, que em tão altas pessoas se faz indispensável». A pouco e pouco a criança seria habituada a reduzir, sem prejuízo de sua saúde, as suas horas de sono, começando o dia bem cedo, de maneira a poder "cumprir com as suas obrigações de cristão, de filho e de príncipe»: ir beijar a mão a seus avós e pais depois de rezar as orações matinais e, se possıvel, assistir à missa com sua mãe, voltando imediatamente para o seu quarto, "sem que nunca se perca de vista na ida e na volta, de sorte que seja distraido ou divertido para conversações, que lhe tomem o tempo desnecessariamente».

O segundo passo dizia respeito ao controlo da gestualidade no convívio com os seus súbditos e neste ponto as regras são claramente formuladas. A primeira aborda a compostura do corpo, "a figura em que estará enquanto lhe falarem, sem fazer gestos ou jeitos com contorsões contrárias à gravidade e muito mais ao carácter de sua pessoa». A segunda regra domestica o olhar: «quando falar com as ditas pessoas, deve olhar para elas fixamente sem pôr os olhos no chão, como envergonhado, ou noviço, e sem distrair a vista com demora para outros objectos». A terceira regra ensina o tom de que deve usar: "se deve propor sempre que falar aos vassalos a ideia não só de lhes comprimir respeito com aquela modéstia e compostura de acções, mas também de lhes ganhar o amor pela afabilidade, com que os receber». Essa afabilidade não é incompatível com a dignidade de príncipe e ela se deve exteriorizar "por uma ou duas palavras obrigantes ou ainda somente usando de um certo arzinho afável, o que quando se lhe fizer algum serviço, ou se lhe disser coisa digna de reconhecimento, não é impróprio nos príncipes, mas neles tão natural como o é a sua grandeza».

A organização do tempo e o controlo da gestualidade no relacionamento com os súbditos constituiam por assim dizer a base sobre a qual assentavam as prescrições substantivas desta primeira educação.

Levando em conta o gosto das crianças desta idade por ouvir contar histórias, procurava-se canalizar este pendor de maneira a que o Príncipe aprendesse desse modo coisas «oportunas e necessárias", e em primeiro lugar os princípios religiosos. Neste campo todos os cuidados seriam poucos, "para eleger e praticar o virtuoso meio entre duas perigosas extremidades da irreligião e do fanatismo, porque é certo que uma e outra têm levado após de si as ruínas dos Reinos e dos Impérios». A prudência neste ponto, como diz o documento, 
"pertence mais principalmente ao cuidado do confessor", mas náo deixam as instruções de dar também uma orientação religiosa: "sendo da grandeza de Deus Nosso Senhor, dar obras da sua omnipotência na criação do mundo e da religião cristã, que professamos, as primeiras ideias que se devem dar ao Pr.ncipe serão para lhe fazer ver, e imprimir na memória a excelente história do Velho e Novo Testamento representado com figuras pelo insigne Theargo Sacy, porque cada figura é um útil registo para a recreação das primeiras idades, e para nelas se imprimirem assim as ideias como as noções dos seus significados». Narrativa e imagem se conjugavam portanto no ensino da religião naquilo que ela podia apresentar de mais concreto e adequado à idade do Príncipe.

Se a primeira formação religiosa pertencia à alçada clo confessor, Fr. Manuel do Cenáculo, aos outros responsáveis pela educação do Príncipe cabia apenas desviá-lo do que podia "distrair lhe o ânimo e fazê-lo declinar ou para a incredulidade, ou para a incontinência, sem contudo se lhe abaterem os espíritos e se lhe tirar o brio juvenil». Pedia-se aos educadores uma atitude equilibrada, permissiva de "tudo o que nos limites da cristandade e da nobreza costuma permitir-se aos príncipes".

Enquanto para o ensino religioso se recorria à narrativa e à imagem, para a transmissão de outros tipos de conhecimentos se utilizava uma forma discursiva denominada "conversações familiares", versando não sobre questões abstractas e metafísicas, mas sobre "coisas nobres, úteis, práticas", ou seja, sobre temas de interesse para um futuro monarca, como por exemplo o tema da reputação, "que é o calor natural que vivifica os corpos das monarquias, que por isso foi sempre a mais preciosa e recatada menina dos olhos dos maiores monarcas do mundo, porque viram que a reputação pode mais do que os exércitos para a conservação das monarquias, ¿ porque sem ela não pode príncipe algum subsistir sobre o trono".

Vemos assim que o primeiro princ pio político a ser incutido nas conversações do Príncipe com os seus educadores ć o princípio fundamental das monarquias ilustradas: o rei não reina pela força dos seus exércitos, mas sim pela forca do seu nome, ou seja, pelo seu prestígio. Princípio válido do ponto de vista da política interna, deve contudo ser descartado da política externa, onde a força dos exércitos é absolutamente necessária. Colocada a questão de saber "se é poss vel que um reino desarmado possa ter segurança, para se conservar somente pela razão do direito, com que lhe assistem os tratados políticos, ou os títulos hereditários», a resposta é 
negativa e recorre-se à história de Portugal para demonstrar essa impossibilidade.

Nestas instruções, a história portuguesa é didacticamente dividida em quatro épocas, sendo indicados os autores a serem lidos para o conhecimento de cada uma delas. A colecção de crónicas compiladas por Duarte Nunes de Leão mosrará ao discípulo «os exercícios, as guerras e as batalhas dos primeiros monarcas destes Reinos, com que não só se defenderam dos mouros e vizinhos, mas obrigaram uns e outros a sairem do nosso continente». João de Barros e uma Vida do Infante D. Henrique publicada em 1748 forneciam o material para se resumir "Os gloriosos progressos das poderosas armadas dos Senhores Reis D. João II e D. Manuel».

A doutrinação pombalina aparece claramente no trecho seguinte: "Na terceira época se devem substanciar os factos dos duzentos anos com que os intitulados jesuítas aniquilaram as armas e a milícia, mostrando que pela falta dela, foi Portugal sujeito a Castela, e perdeu com a liberdade a glória, a honra e a fama que tinha adquirido enquanto foi armado, provando-se tudo isto com o outro compêndio extraído da $1 .^{2}$ parte da Dedução Cronológica e Analítica». Responsabilizados assim os jesuítas pela desmilitarização do Reino de Portugal e sua consequente decadência e aniquilação, deveriam os educadores do Príncipe concluir o resumo dos fastos portugueses com a referência à brilhante recuperação militar e económica da monarquia: "Na quarta e última época se deve ponderar a restauração da glória e nome português, da sua navegação e florescente comércio nestes últimos dezoito anos, depois que as tropas, a marinha, as praças e as fortalezas do Reino se puseram no respeitável estado, em que hoje se acham, extraindo-se para assim se mostrar a substância na divisão 15. ${ }^{2}$ da dita Dedução».

Todas as conversações pedagógicas sobre a História de Portugal visavam portanto inculcar no pequeno Príncipe a ideia de que os reinos não conseguem sobreviver se não possuirem um poder militar capaz de os defender das agressões perigosas e externas. Um rei não reina sobre os seus vassalos pela força das armas, mas um reino sem elas está condenado à destruição. Atribuindo-se aos jesuítas o espírito anti-militarista, demonstrava-se simultaneamente a sua responsabilidade na perda da independência com a sujeição a Castela.

Encontramos ainda nestas instruções a afirmação do carácter propedêutico da Geometria, que igualmente aparece em textos daquele que foi o confessor e depois mestre do Príncipe da Beira, Fr. Manuel do Cenáculo. Mas essa defesa do espírito e método geométricos termina, numa ruptura nitida- 
mente ideológica, com mais um ataque aos jesuítas: «Em outras das sobreditas conversações se deve reflectir sobre a indispensável necessidade que os príncipes têm de se aplicarem ao estudo da Geometria, porque só com a ciência dela podem discorrer e obrar sobre princípios certos e demonstrados, e podem conhecer e reprovar os sofismas, com que muitos homens por lisonja, por interesse próprio, e por falso zelo intentam enganá-los, fazendo-se compreender sobre isto ao Príncipe, que por falta de conhecimento desta utilíssima arte esses monarcas precipitam as suas Reais Pessoas e seus Reinos nas maiores ruínas, bastando para a sua convicção, a infaustosíssima guerra, com que os denominados jesuítas levaram à Africa o infelicíssimo rei D. Sebastião para deixar, como deixou, sepultadas naquelas infames terras com a sua Real Pessoa, a honra, a fama, o cabedal e a liberdade destes Reinos e seus Domínios».

Como último exemplo de temas adequados às conservações com o Príncipe, é referida a Geografia da Europa, devendo a criança aprender a localizar no globo os vários reinos, mas a critério dos educadores poderiam ser escolhidos outros assuntos de interesse para esta fase da educação daquele que se cogitava seria o próximo herdeiro do trono.

Não deixam as instruções de insistir na necessidade de todos estes conhecimentos serem ministrados de maneira agradável e não por «um estudo forçado e contínuo, que lhes faça criar aversão às lições que há-de receber». Daí a vantagem de os vários temas serem introduzidos sob a forma de conversações, "porque este modo não só é o mais suave e agradável, mas também o que mais aproveita». Levando em conta o facto de que nenhuma criança daquela idade poderia passar sem momentos de recreação neste programa de estudos, ficavam reservadas ao divertimento do Príncipe as três horas que se seguiam ao jantar.

E interessante notar que se prevê uma certa rebeldia do Príncipe perante toda esta programação, dada "a sua viveza natural e o hábito, em que se acha de altercar razões e sustentar porfias com as criadas dos quartos, aonde até agora assistia». A solução para acabar com essas tentativas de desobediência seria toda uma argumentação tendente a mostrar à criança a inutilidade da sua resistência às ordens recebidas de seu avô e rei.

Como podemos observar, estas instruções para a educação do Príncipe da Beira deixam de lado completamente toda a parte por assim dizer técnica da sua instrução. 0 futuro herdeiro do trono tinha um mestre de ler e escrever que se encarregaria da sua alfabetização, mas este ponto não mere- 
cia especiais cuidados. 0 importante era formar o espírito infantil nos moldes adequados à política pombalina: desenvolver nele um sentimento religioso equilibrado entre os extremos da incredulidade e do fanatismo, incutir-lhe a ideia de que um monarca tem de defender o seu trono com o seu prestígio e o seu reino com os seus exércitos, provocar a aversão pelos jesuítas, responsáveis por todos os insucessos de Portugal, sobretudo o desastre de Alcácer-Quibir e a sujeição a Castela, começar a desenvolver o espírito geométrico $\left({ }^{7}\right)$, único capaz de levar um futuro rei a raciocinar sem se prender aos sofismas daqueles que aspiram a influir nas suas decisões. Averiguar em que medida estas instruções foram efectivamente observadas e de que forma se processou na realidade a educação do Príncipe da Beira, D. José, seria uma pesquisa necessária para que se pudesse medir a distância entre os projectos pombalinos e a sua realização.

( ${ }^{7}$ Cenáculo definia claramente o que entendia por «espírito geométrico»: «Este espírito consiste em tomar por princípios e axiomas coisas universalmente verdadeiras, cousas sem questão, e admitidas por certas, e daí trazer suas proposiçōes intentadas, e descobrir incógnitas. Estabelecidas as primeiras proposiçôes gerais deduzem-se outras mais simples, e deste modo se vão encadeando outras segundo sua ordem natural até concluir». Este espírito geométrico só se podia desenvolver e aplicar a qualquer campo ou ciência por quem cultivasse a Geometria, «que dirige a mente para descobrir a falsidade, para a fazer ver aos outros, para os chamar ao bom caminho» (in Caeiro, ob. cit., pp. 170-171). 